Article

\title{
Food Insecurity Is Associated with Mental-Physical Comorbidities among U.S. Adults: NHANES 2013 to 2016
}

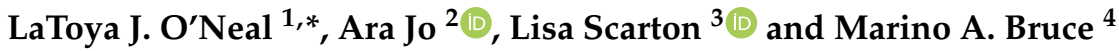 \\ 1 Department of Family, Youth and Community Sciences, Institute of Food and Agricultural Sciences, College \\ of Agricultural and Life Sciences, University of Florida, Gainesville, FL 32611, USA \\ 2 Department of Health Services Research, Management and Policy, College of Public Health and Health \\ Professions, University of Florida, Gainesville, FL 32611, USA; ara13j@phhp.ufl.edu \\ 3 Department of Family, Community and Health Systems Science, College of Nursing, University of Florida, \\ Gainesville, FL 32611, USA; lscarton@ufl.edu \\ 4 Department of Behavioral and Social Sciences, College of Medicine, University of Houston, \\ Houston, TX 77004, USA; mabruce@central.uh.edu \\ * Correspondence: latoya.oneal@ufl.edu
}

Citation: O'Neal, L.J.; Jo, A.; Scarton, L.; Bruce, M.A. Food Insecurity Is Associated with Mental-Physical Comorbidities among U.S. Adults: NHANES 2013 to 2016. Int. J. Environ. Res. Public Health 2022, 19, 1672. https://doi.org/10.3390/ ijerph19031672

Academic Editors: Paul B. Tchounwou, Roland J. Thorpe, Jr., Paul Archibald, Marino A. Bruce and Haley Barge

Received: 16 December 2021

Accepted: 29 January 2022

Published: 1 February 2022

Publisher's Note: MDPI stays neutral with regard to jurisdictional claims in published maps and institutional affiliations.

Copyright: (C) 2022 by the authors. Licensee MDPI, Basel, Switzerland. This article is an open access article distributed under the terms and conditions of the Creative Commons Attribution (CC BY) license (https:// creativecommons.org/licenses/by/ $4.0 /)$.

\begin{abstract}
The co-occurrence of mental and physical conditions has increased significantly during the last decade. However, research examining the influence of social factors such as food insecurity is limited. The purpose of this study was to examine the association between food insecurity and mental-physical comorbidity status among U.S. adults. Data for this analysis were drawn from the National Health and Nutrition Examination Survey (NHANES) for the years 2013-2016. Respondents ages 18 and older who reported at least one of three chronic conditions (i.e., type 2 diabetes mellitus, hypertension, and hyperlipidemia) and responded to a nine-item depression scale were included in the analytic sample. The prevalence of food insecurity among those with depression and a cardiometabolic condition was $34 \%$ compared to $13 \%$ among those with a cardiometabolic condition only. Findings from multinomial logistic regression models indicated that food insecurity was associated with higher risk of mental-physical comorbidity (OR: 3.6, 95\% CI: 2.26-5.76). Respondents reporting poor diet and poor self-reported health had higher odds of comorbid depression and cardiometabolic conditions. Female respondents had increased odds of comorbid depression and cardiometabolic conditions. Food insecurity is associated with co-occurring depression and cardiometabolic disease and may have implications for disease management.
\end{abstract}

Keywords: food insecurity; comorbidity; depression; chronic conditions; NHANES; cardiometabolic conditions

\section{Introduction}

Food insecurity is a critical risk factor for poor health outcomes, especially those related to dietary intake [1,2]. The significant association between household food insecurity and cardiometabolic comorbidity is a growing health concern, as the prevalence of U.S. adults living with multiple chronic conditions has increased significantly over the last two decades $[3,4]$. Depression is one of the chronic conditions that co-occurs with a number of cardiometabolic diseases (type 2 diabetes mellitus (T2DM), hypertension, and hyperlipidemia) linked to food insecurity. Recent data indicate that the proportion of individuals with depression and T2DM is 15.4\% [5], that the prevalence of depression with hypertension is $26.8 \%$ [6], and that depression with hyperlipidemia is $29.7 \%$ among some populations [7]. The prevalence of mental-physical comorbidities is troubling given that individuals who experience depression along with chronic cardiometabolic conditions tend to have higher morbidity, mortality, and healthcare expenses [8-10] than individuals with a single chronic disease. Depression has been shown to negatively impact adherence and selfactivation, which are essential for managing T2DM, heart disease, and hypertension [11-14]. 
Social factors such as food insecurity have been found to impact health $[1,2,15,16]$, yet, few studies have examined specific associations between food insecurity, depression, and chronic disease. Further, none have examined the relationship between food insecurity and comorbid depression and cardiometabolic conditions among a nationally representative sample. Identifying risk factors associated with co-occurring mental and physical conditions requires attention, as this type of comorbidity can accelerate disease progression and contribute to the development of complications and more severe diseases (e.g., chronic kidney disease, cardiovascular disease) that exacerbate the costs and burdens to individuals, families, and communities [17-21].

The purpose of this study is to (1) characterize chronic cardiometabolic conditions and their co-occurrence with depression in a nationally representative sample of the U.S. population and (2) assess the salience of food insecurity on chronic cardiometabolic conditions and mental-physical comorbidities among adults in the U.S. We expect food insecurity to be associated with a greater likelihood of mental-physical comorbidities.

\section{Materials and Methods}

\subsection{Sample}

Data for this analysis were drawn from the National Health and Nutrition Examination Survey (NHANES) for the years 2013-2016. The NHANES uses multistage probability complex sample design to establish a nationally representative sample of civilian, noninstitutionalized persons in the U.S. Data for NHANES were collected via household survey and physical examination and included sociodemographic and clinical information. The analytic sample for this study was limited to adults ages 18 and older who reported medical conditions of three chronic diseases (i.e., T2DM, hypertension, and hyperlipidemia) and responded to a nine-item depression scale. Participants who have missing values on one of the targeted medical conditions $(n=3029)$ and pregnant women $(n=85)$ were excluded. The analytic sample for this study consisted of 8948 participants. This study was approved as exempt by the Institutional Review Board at the University of Florida.

\subsection{Study Measures}

\subsubsection{Comorbidity Status}

Mental-physical comorbidity status was the primary outcome for the study. This threecategory measure was derived to capture whether respondents had no chronic conditions, at least one chronic cardiometabolic condition (hypertension, T2DM, or hyperlipidemia), or depression and at least one chronic cardiometabolic condition. The depression data for the measure was derived from the score on the Patient Health Questionnaire, a nine-item (PHQ-9) quick depression assessment used to identify respondents with depression [22,23]. Individuals with scores 10 or higher were considered depressed [23]. The cardiometabolic component of the measure was derived from responses to items asking if respondents had been told by a doctor that they have hypertension, T2DM, or hyperlipidemia. Respondents were assigned to one of three categories, "no disease" were individuals who did not report a chronic cardiometabolic condition or depression, "only chronic disease" were respondents who did not classify as depressed but reported having a chronic cardiometabolic condition, and "chronic disease with depression" were individuals who were classified as depressed and reported having at least one chronic cardiometabolic condition.

\subsubsection{Food Insecurity}

The primary independent variable for this study was food insecurity. Adult food insecurity was derived from responses to the 10 adult questions of the 18 items on the Food Security Survey Module (FSSM) [24]. Responses were categorized into four levels based on the number of affirmative responses to 10 items (i.e.., full food security, 0 points; marginal food security, 1-2 points; low food security, 3-5 points; and very low food security, 6-10 points) [24]. 


\subsubsection{Other Independent Variables}

Weight status was a categorical variable derived from body mass index that is calculated by dividing weight in centimeters by height in meters squared. The specific categories were underweight (BMI < 18.5), normal weight (BMI = 18.5 to 24.9), overweight $(\mathrm{BMI}=25.0-29.9)$, or obese $(\mathrm{BMI} \geq 30)$ [25]. Health behaviors in this study included factors known to be associated with cardiometabolic health. Diet, physical activity, sedentary behavior, and smoking were assessed using self-report. Diet was measured by a single-item measure asking respondents; "How healthy is your diet?" with five categories ranging from "excellent" to "poor". Physical activity was measured by two items asking respondents; "How much time do you spend doing vigorous-intensity recreational activities on a typical day?" and "How much time do you spend doing moderate-intensity recreational activities on a typical day?". Physical activity guidelines for Americans suggests 75 min a week for vigorous-intensity or $150 \mathrm{~min}$ a week for moderate-intensity activity [26]. Thus, the physical activity variable was categorized into two categories, met the guidelines or did not meet the guidelines. The sedentary lifestyle variable was measured by a single-item measure asking, "How much time do you usually spend sitting on a typical day?". It was recoded as a dichotomous variable into having a sedentary lifestyle (i.e., sitting for $180 \mathrm{~min}$ per day) or not having a sedentary lifestyle. [27]. Health status was represented by two categories, good to excellent and fair or poor. Tobacco use was coded into three categories: never a smoker, former smoker, and current smoker. Usual source of care was operationalized as having a place to go when in need of care, such as a hospital, doctor's office, etc., or none.

\subsubsection{Study Covariates}

Study covariates included self-reported demographic data and socioeconomic status. Age was a continuous variable. Sex was a dichotomous variable (i.e., male/female). Race/ethnicity was measured by a categorical variable with categories for individuals identifying themselves as non-Hispanic White, non-Hispanic Black, Hispanic, and Other. Marital status was a categorical variable with respondents assigned to one of three categories based on their selection-single who never married; single who were widowed, separated or divorced; and married or currently living with a partner. Education was modified into three levels (i.e., less than high school, high school graduate/GED or equivalent, and some college or above). Poverty level was determined based upon poverty to income ratio (PIR) and a cutoff point of 1.0 distinguished between poor and rich [28]. Family size was used as a categorical variable based on the number of people reported in the household and categorized as 1 representing a single individual, 2 representing a family of two, 3 representing a family of three, and 4 or more representing a family of 4 or more people.

\subsection{Statistical Analysis}

Sample characteristics were described by multiple t-tests and chi-square tests. All estimates were weighted to adjust for the differential probabilities of sampling and nonresponse, to represent the total civilian, noninstitutionalized U.S. population [29]. Estimates derived from a sample size smaller than the recommended lower limit in the NHANES analytic guidelines were considered unreliable. Unadjusted and adjusted multinomial logistic regression model controlling for age, sex, and race/ethnicity were estimated to evaluate the significant association of social and behavioral factors and multiple chronic conditions status. Results are expressed as odds ratios with 95\% confidence intervals. All analyses were performed using SAS-callable SUDAAN, version 13 (Cary, NC, USA) and all estimates and statistical tests were adjusted for the complex NHANES survey design based upon the National Center for Health Statistics (NCHS) recommendation [30]. 


\section{Results}

Sociodemographic and cardiometabolic characteristics of respondents by household food security status are shown in Table 1 . Approximately $15 \%$ of the sample reported low to very low food security (food insecurity). The proportion of non-Hispanic Black and Hispanic adults with food insecurity was 2-3 times higher than non-Hispanic White adults. Respondents who were single, including never married and widowed, separated, or divorced, had a higher prevalence of food insecurity than those who were married or living with a partner. Significant differences in percentages were also found by socioeconomic status (SES). The percentage of adults experiencing food insecurity was approximately $30 \%$ among those with less than a high school diploma and only $10 \%$ among those with some college or above. Concerning poverty level, 37\% of respondents who were below the poverty level reported food insecurity compared to $11 \%$ of those above the poverty level. While a family size of two seemed to have a protective effect, as family size increased so did the percentage of the sample experiencing food insecurity.

Table 1. Characteristics of study population (\%) by food security status using NHANES 2013-2016 data.

\begin{tabular}{|c|c|c|c|c|c|}
\hline & $\begin{array}{l}\text { Full Security } \\
\quad(n=7863)\end{array}$ & $\begin{array}{c}\text { Marginal } \\
\text { Security } \\
(n=1353)\end{array}$ & $\begin{array}{l}\text { Low Security } \\
\qquad(n=1275)\end{array}$ & $\begin{array}{l}\text { Very Low } \\
\text { Security } \\
(n=963)\end{array}$ & $p$-Value \\
\hline Food Security Status & 74.9 & 9.8 & 8.6 & 6.7 & \\
\hline \multirow[t]{2}{*}{ Age * (mean $)$} & 48.3 & 41.1 & 41.2 & 40.5 & $<0.01$ \\
\hline & & Sex & & & \\
\hline Male & 75.6 & 9.4 & 8.2 & 6.8 & \multirow{2}{*}{ NS } \\
\hline \multirow[t]{2}{*}{ Female } & 74.3 & 10.1 & 9.0 & 6.7 & \\
\hline & & Race/Ethnicity * & & & \\
\hline NH White & 81.3 & 7.3 & 5.8 & 5.5 & \multirow{4}{*}{$<0.001$} \\
\hline NH Black & 60.5 & 15.9 & 13.0 & 10.5 & \\
\hline Hispanic & 56.4 & 15.8 & 18.3 & 9.6 & \\
\hline \multirow[t]{2}{*}{ Others } & 77.1 & 9.6 & 7.2 & 6.1 & \\
\hline & & Marital Status * & & & \\
\hline Married, living with partner & 79.7 & 8.2 & 7.1 & 5.0 & \multirow[t]{3}{*}{$<0.001$} \\
\hline Widowed, separated, divorced & 69.2 & 11.2 & 10.1 & 9.5 & \\
\hline \multirow[t]{2}{*}{ Never married } & 67.7 & 11.5 & 11.3 & 9.5 & \\
\hline & & Education * & & & \multirow{5}{*}{$<0.001$} \\
\hline $\begin{array}{l}\text { Less than high } \\
\text { school }\end{array}$ & 56.6 & 13.8 & 18.5 & 11.2 & \\
\hline High school & & & & & \\
\hline $\begin{array}{l}\text { graduate/GED } \\
\text { or equivalent }\end{array}$ & 68.7 & 12.1 & 10.2 & 9.0 & \\
\hline \multirow[t]{2}{*}{$\begin{array}{c}\text { Some college } \\
\text { or above }\end{array}$} & 82.4 & 7.4 & 5.3 & 4.8 & \\
\hline & & Poverty Level * & & & \multirow{4}{*}{$<0.001$} \\
\hline Poor $($ PIR < 1) & 43.7 & 19.2 & 18.4 & 18.8 & \\
\hline \multirow[t]{2}{*}{ Rich (PIR $\geq 1$ ) } & 81.5 & 7.8 & 6.3 & 4.5 & \\
\hline & & Family Size * & & & \\
\hline 1 & 73.1 & 9.6 & 7.4 & 9.8 & \multirow{4}{*}{$<0.001$} \\
\hline 2 & 84.8 & 6.2 & 5.3 & 3.8 & \\
\hline 3 & 73.0 & 11.3 & 8.6 & 7.1 & \\
\hline \multirow{2}{*}{$4+$} & 68.7 & 12.1 & 12.3 & 7.0 & \\
\hline & & $\operatorname{BMI}\left(\mathrm{kg} / \mathrm{m}^{2}\right) *$ & & & \multirow{5}{*}{$<0.001$} \\
\hline Underweight & 61.3 & 17.3 & 12.1 & 9.3 & \\
\hline Normal & 77.42 & 9.1 & 7.3 & 6.3 & \\
\hline Overweight & 78.0 & 9.1 & 7.6 & 5.4 & \\
\hline \multirow[t]{2}{*}{ Obese } & 70.7 & 10.6 & 10.5 & 8.2 & \\
\hline & & Comorbidity Status * & & & \multirow{4}{*}{$<0.001$} \\
\hline No disease & 78.0 & 9.5 & 7.3 & 5.2 & \\
\hline Only chronic disease & 78.5 & 8.3 & 7.7 & 5.6 & \\
\hline Chronic disease with depression & 50.8 & 14.7 & 14.6 & 19.9 & \\
\hline
\end{tabular}

* Indicates significance.

There were significant differences in the percentages of food insecurity reported by weight status. Respondents who reported being underweight had the highest rate of food insecurity at $21 \%$, followed by those who reported obesity at $19 \%$. Food insecurity was $14 \%$ among those reporting normal weight and 13\% among those reporting overweight. 
Among those who reported no disease, the percentage of food insecurity was $13 \%$. The percentage of food insecurity was significantly higher at 35\% among respondents reporting chronic disease with depression.

Significant differences in food security status were also associated with health lifestyle behaviors, as shown in Table 2 . Approximately $60 \%$ of respondents reporting fair or poor diets also reported food insecurity. Similarly, respondents reporting fair or poor health reported higher rates of food insecurity. Food insecurity was higher among current smokers when compared to those who stopped smoking or never smoked. Those without a usual source of care reported food insecurity at 25\% compared to $14 \%$ among those with a usual source of care.

Table 2. Health lifestyle behaviors by food security status using NHANES 2013-2016 data.

\begin{tabular}{|c|c|c|c|c|c|}
\hline & $\begin{array}{l}\text { Full Security } \\
\quad(n=7863)\end{array}$ & $\begin{array}{c}\text { Marginal } \\
\text { Security } \\
(n=1353)\end{array}$ & $\begin{array}{l}\text { Low Security } \\
\qquad(n=1275)\end{array}$ & $\begin{array}{l}\text { Very Low } \\
\text { Security } \\
(n=963)\end{array}$ & $p$-Value \\
\hline \multicolumn{6}{|c|}{ Healthy Diet* } \\
\hline Excellent & 85.5 & 4.9 & 5.1 & 4.5 & \multirow{5}{*}{$<0.001$} \\
\hline Very Good & 86.23 & 6.9 & 5.0 & 1.8 & \\
\hline Good & 77.0 & 9.9 & 7.7 & 5.5 & \\
\hline Fair & 63.8 & 11.6 & 15.0 & 9.6 & \\
\hline Poor & 51.5 & 12.7 & 15.5 & 20.4 & \\
\hline \multicolumn{6}{|c|}{ Health Status * } \\
\hline $\begin{array}{c}\text { Good or } \\
\text { above }\end{array}$ & 78.6 & 9.3 & 6.9 & 5.2 & \multirow[t]{2}{*}{$<0.001$} \\
\hline Fair or poor & 59.7 & 11.5 & 14.8 & 14.0 & \\
\hline \multicolumn{6}{|c|}{ Tobacco Use * } \\
\hline $\begin{array}{l}\text { Never } \\
\text { smoker }\end{array}$ & 78.5 & 9.0 & 7.9 & 4.7 & \multirow{3}{*}{$<0.001$} \\
\hline $\begin{array}{l}\text { Former } \\
\text { smoker }\end{array}$ & 81.0 & 7.6 & 6.5 & 4.8 & \\
\hline $\begin{array}{l}\text { Current } \\
\text { smoker }\end{array}$ & 58.9 & 13.4 & 12.9 & 14.8 & \\
\hline \multicolumn{6}{|c|}{ Usual Source of Care * } \\
\hline Yes & 77.5 & 8.9 & 8.0 & 6.0 & \multirow{2}{*}{$<0.001$} \\
\hline No & 61.0 & 14.1 & 14.1 & 10.8 & \\
\hline
\end{tabular}

Results from multinomial logistic regression models are presented in Table 3. Several demographic, social, and health lifestyle factors were significantly associated with increased risk of chronic cardiometabolic conditions and mental-physical comorbidities relative to having no disease. With respect to sex, the odds for females were lower than the odds for males with only chronic disease relative to no disease. Non-Hispanic Black adults had greater odds than non-Hispanic White adults with only chronic disease relative to no disease. There were no significant differences found by marital status, education, poverty level, or family size, food security, or healthy diet with only chronic disease relative to having no disease.

For perceived health status, those reporting fair or poor health had higher odds than those reporting good to excellent health with only chronic disease relative to having no disease. Respondents who reported being a current smoker had 1.4 higher odds compared to those who never smoked with only chronic disease relative to having no disease. Additionally, those who reported having a usual source of care had higher odds than those who do not have a usual source of care with only chronic disease relative to no disease. 
Table 3. Results of multinomial logistic regression for factors associated with mental-physical comorbidity status among U.S. adults using NHANES 2013-2016 data.

\begin{tabular}{|c|c|c|}
\hline \multirow{2}{*}{ Factors } & \multicolumn{2}{|c|}{ Odds Ratio (95\% CI) } \\
\hline & Only Chronic Disease & $\begin{array}{c}\text { Chronic Disease with } \\
\text { Depression }\end{array}$ \\
\hline \multirow[t]{2}{*}{ Age * } & $1.1(1.06-1.08)^{*}$ & $1.1(1.04-1.09)^{*}$ \\
\hline & Sex* & \\
\hline & 1.00 (Ref) & 1.00 (Ref) \\
\hline \multirow[t]{2}{*}{ Female } & $0.8(0.67-0.99)^{*}$ & $1.7(1.06-2.84)$ * \\
\hline & Race/Ethnicity * & \\
\hline NH White & $1.00(\operatorname{Ref})$ & 1.00 (Ref) \\
\hline NH Black & $1.4(1.10-1.66)$ * & $1.1(0.72-1.84)$ \\
\hline Hispanic & $0.8(0.62-1.12)$ & $0.5(0.36-0.79) *$ \\
\hline \multirow[t]{2}{*}{ Others } & $1.1(0.86-1.43)$ & $1.1(0.60-2.01)$ \\
\hline & Marital Status & \\
\hline Married, living with partner & 1.00 (Ref) & 1.00 (Ref) \\
\hline Widowed, separated, divorced & $1.0(0.82-1.25)$ & $1.4(0.87-2.32)$ \\
\hline \multirow[t]{2}{*}{ Never married } & $1.1(0.75-1.55)$ & $0.9(0.50-1.68)$ \\
\hline & Education & \\
\hline \multirow{3}{*}{$\begin{array}{c}\text { Less than high school } \\
\text { High school graduate/GED or } \\
\text { equivalent } \\
\text { Some college or above }\end{array}$} & 1.00 (Ref) & 1.00 (Ref) \\
\hline & $1.0(0.82-1.24)$ & $0.7(0.46-1.03)$ \\
\hline & $1.0(0.78-1.31)$ & $0.6(0.35-1.02)$ \\
\hline \multirow{4}{*}{$\begin{array}{l}\text { Poor }(\mathrm{PIR}<1) \\
\text { Rich }(\mathrm{PIR} \geq 1)\end{array}$} & Poverty Level & \\
\hline & 1.00 (Ref) & 1.00 (Ref) \\
\hline & $0.9(0.75-1.19)$ & $1.0(0.62-1.46)$ \\
\hline & Family Size & \\
\hline 1 & 1.00 (Ref) & 1.00 (Ref) \\
\hline 2 & $1.1(0.81-1.66)$ & $1.3(0.71-2.43)$ \\
\hline 3 & $0.8(0.61-1.11)$ & $1.2(0.68-2.11)$ \\
\hline \multirow[t]{2}{*}{$4+$} & $1.0(0.68-1.35)$ & $1.0(0.59-1.62)$ \\
\hline & Food Security* & \\
\hline Full & 1.00 (Ref) & 1.00 (Ref) \\
\hline Marginal & $1.2(0.81-1.66)$ & $2.4(1.06-5.43) *$ \\
\hline Low & $1.2(0.77-1.86)$ & $2.2(1.23-3.95)$ * \\
\hline \multirow[t]{2}{*}{ Very low } & $1.5(0.99-2.36)$ & $3.6(2.29-5.76) *$ \\
\hline & Healthy Diet* & \\
\hline Excellent & 1.00 (Ref) & 1.00 (Ref) \\
\hline Very Good & $0.8(0.54-1.30)$ & $0.7(0.28-1.63)$ \\
\hline Good & $1.2(0.69-1.95)$ & $1.6(0.81-3.08)$ \\
\hline Fair & $1.7(1.00-2.91)$ & $2.8(1.34-5.85) *$ \\
\hline \multirow[t]{2}{*}{ Poor } & $1.7(0.87-3.45)$ & $4.3(1.47-12.59)$ * \\
\hline & Health Status * & \\
\hline Good or above & 1.00 (Ref) & 1.00 (Ref) \\
\hline \multirow[t]{2}{*}{ Fair or poor } & $2.0(1.57-2.56)^{*}$ & $6.3(4.15-9.71) *$ \\
\hline & Tobacco Use * & \\
\hline Never smoker & 1.00 (Ref) & 1.00 (Ref) \\
\hline Former smoker & $1.4(1.08-1.70) *$ & $1.6(1.04-2.38)$ * \\
\hline \multirow[t]{2}{*}{ Current smoker } & $1.4(1.04-1.92)$ * & $2.2(1.46-3.47)$ * \\
\hline & Usual Source of Care * & \\
\hline No & $1.00(\operatorname{Ref})$ & 1.00 (Ref) \\
\hline Yes & $1.6(1.19-2.08)$ * & $2.8(1.56-4.84) *$ \\
\hline
\end{tabular}


As it relates to mental-physical comorbidities, the odds for females were $70 \%$ greater than the corresponding odds for males with chronic disease and depression relative to no disease. The odds for Hispanic adults were lower than non-Hispanic White adults with mental-physical comorbidities relative to no disease. There were no significant differences found by marital status, education, poverty level, or family size.

Overall, food insecurity was significant for respondents with mental-physical comorbidities when compared to the no disease group. Specifically, the odds for highly food insecure respondents relative to food secure sample members were 3.6 (CI: 2.26-5.76) times greater for having mental-physical comorbidities relative to no disease. Those reporting a poor diet had 4.3 times higher odds than respondents reporting an excellent diet with mental-physical comorbidities relative to no disease. Additionally, the odds for respondents who perceived their health as fair or poor were 6.3 times higher than the odds for those perceiving their health as good to excellent with mental-physical comorbidities relative to no disease.

Behavioral factors such as smoking status including being a current or former smoker and having a usual source of care were both significantly associated with mental-physical comorbidities relative to having no disease. Current smokers had 2.2 higher odds compared to those who never smoked with mental-physical comorbidities relative to no disease. Respondents who reported having a usual source of care had 2.8 higher odds compared to those reporting no usual source of care with mental-physical comorbidities relative to no disease.

\section{Discussion}

Considering the prevalence of chronic disease comorbidities, including co-occurring depression and cardiometabolic comorbidity, among U.S. adults, it is critical to identify risk factors that may influence disease management, progression, and long-term health outcomes. This study provides timely and relevant evidence of significant individual, social, and structural level determinants associated with depression and cardiometabolic comorbidities in U.S. adults. The main finding from this study is that food insecurity is significantly associated with greater odds of mental-physical comorbidities relative to no disease.

This finding corresponds to previous research that found food insecurity to be a risk factor for multiple chronic conditions and for depression, in independent analyses [1,4]. This study confirms the association between food insecurity and co-occurring mental and physical comorbidities in a national sample. These findings suggest that increasing food security should be a target for prevention and management of mental-physical comorbidities prior to or along with lifestyle interventions.

The impact of food insecurity on health outcomes is receiving increased attention. However, most food assistance programs and social support programs focus on lowincome families without considering complex clinical status. It is well established that food insecurity is significantly associated with a higher prevalence of depression [1,31] including among those with diabetes [15]. Leung and colleagues [1] found that those without food stamp benefits showed the highest risk of depression. This suggests that additional support including food support and nutrition education, in addition to standard of care, is needed for individuals experiencing food insecurity. Legitimate food support is needed since proper food provision and nutrition counseling can lower healthcare spending and healthcare utilization [32].

These findings also highlight the need for different primary and secondary prevention strategies to effectively address food insecurity amid the rising prevalence of cardiometabolic comorbidities, especially those co-occurring with depression. Characterizing sociodemographic, lifestyle behaviors, and social environmental factors associated with comorbid chronic disease and depression is important for informing and developing targeted intervention research. To our knowledge, this is the first study to examine food insecurity and risk of co-occurring depression and cardiometabolic comorbidities com- 
pared to chronic disease and no disease among a representative sample of U.S. adults. This information is critical for improving prevention and self-management, including adherence and self-activation among those experiencing mental-physical comorbidities.

We also found individual and social factors were associated with mental-physical comorbidities. Age and sex were both associated with comorbidity status. Specifically, those with mental-physical comorbidities were more likely to be older and female. Other studies have also found significant correlations between comorbid depression and chronic disease among women [33]. The current study confirms these findings in a national data set.

Social-level factors such as marital status and family size were also associated with comorbidity status. Single individuals, who were never married or who were divorced/widowed had higher rates of mental-physical comorbidities compared to those who were married or living with a partner. However, individuals who were never married had lower rates of chronic disease overall. Future studies should seek to disentangle these relationships to meet the needs of individuals and families.

Structural-level determinants were associated with mental-physical comorbidities together with individual health lifestyle behaviors, self-reported health, and having a usual source of care. Lower socioeconomic status was associated with a higher rate of mental-physical comorbidities. Moreover, among individuals with depression and cardiometabolic comorbidities, self-perception of health status, food security, and healthy diet were significantly lower when compared to the other groups.

The study has some limitations. First, due to limited variables collected by the NCHS, clinical diagnosis of depression is unknown. However, since this study used a standard depression screener to identify depression, it is reliable. We were unable to separate those with Type 1 versus Type 2 diabetes in the analysis; however, only 5\% of the sample has Type 1 diabetes. Additionally, as with all cross-sectional databases, causal relationships may not be established. Preliminary models included physical activity and sedentary lifestyle as measures of behavioral risk factors. However, due to small sample size less than 30, these significant values are not valid as population estimates. Subsequently, these two behavior variables were excluded in final models. Finally, participants were asked whether they have a usual source of care that may not account for types of services they received for comorbid conditions, which may present imbalanced health outcomes in individuals who received tailored treatment for multiple conditions despite having a usual source of care. Despite the noted limitations, we are confident in our results as they contribute to the growing body of knowledge surrounding mental-physical comorbidities.

\section{Conclusions}

Food insecurity is significantly associated with mental-physical comorbidities. Understanding the risk factors for and relationship between mental-physical comorbidities may assist in improving health promotion approaches by allowing researchers and practitioners to tailor interventions to the needs of specific subgroups. Health practitioners may consider partnerships with community-based organizations serving high-risk populations to provide prevention and management related nutrition education along with screenings to address mental-physical comorbidities. Future research should consider the role of supplemental social programs designed to address food security, as it appears to be contributing to disparities in chronic disease outcomes.

Author Contributions: L.J.O.: conceptualization, methodology, and writing (original, review, and editing); A.J.: conceptualization, formal analysis, methodology, and writing (original, review and editing); L.S.: conceptualization and writing (review and editing); M.A.B.: methodology and writing (review and editing). All authors have read and agreed to the published version of the manuscript.

Funding: This work was supported in part by National Institutes of Health grant R25HL126145 (L.J.O., M.A.B.). 
Institutional Review Board Statement: The study was conducted in accordance with the Declaration of Helsinki and approved by the Institutional Review Board of the University of Florida (IRB201902172; 14 August 2018.

\section{Informed Consent Statement: Not applicable.}

Data Availability Statement: The National Health and Nutrition Examination Survey data are publicly available from the Centers for Disease Control and Prevention.

Conflicts of Interest: The authors declare no conflict of interest.

\section{References}

1. $\quad$ Leung, C.W.; Epel, E.S.; Willett, W.C.; Rimm, E.B.; Laraia, B.A. Household Food Insecurity Is Positively Associated with Depression among Low-Income Supplemental Nutrition Assistance Program Participants and Income-Eligible Nonparticipants. J. Nutr. 2015, 145, 622-627. [CrossRef] [PubMed]

2. Gundersen, C.; Ziliak, J.P. Food Insecurity And Health Outcomes. Health Aff. 2015, 34, 1830-1839. [CrossRef] [PubMed]

3. Boersma, P.; Black, L.I.; Ward, B.W. Prevalence of multiple chronic conditions among US adults, 2018. Prev. Chronic Dis. 2020, 17, 200130. [CrossRef] [PubMed]

4. Palakshappa, D.; Speiser, J.L.; Rosenthal, G.E.; Vitolins, M.Z. Food Insecurity Is Associated with an Increased Prevalence of Comorbid Medical Conditions in Obese Adults: NHANES 2007-2014. J. Gen. Intern. Med. 2019, 34, 1486-1493. [CrossRef]

5. Chima, C.C.; Salemi, J.L.; Wang, M.; Mejia de Grubb, M.C.; Gonzalez, S.J.; Zoorob, R.J. Multimorbidity is associated with increased rates of depression in patients hospitalized with diabetes mellitus in the United States. J. Diabetes Complicat. 2017, 31, 1571-1579. [CrossRef]

6. Li, Z.; Li, Y.; Chen, L.; Chen, P.; Hu, Y.; Wang, H. Prevalence of depression in patients with hypertension: A systematic review and meta-analysis. Medicine 2015, 94, e1317. [CrossRef]

7. Lochner, K.A.; Cox, C.S. Prevalence of Multiple Chronic Conditions Among Medicare Beneficiaries. Prev. Chronic. Dis. 2010, 10, 120137. [CrossRef]

8. Hajat, C.; Stein, E. The global burden of multiple chronic conditions: A narrative review. Prev. Med. Rep. 2018, 12, 284-293. [CrossRef]

9. Egede, L.E.; Ellis, C. Diabetes and depression: Global perspectives. Diabetes Res. Clin. Pract. 2010, 87, 302-312. [CrossRef]

10. Vogeli, C.; Shields, A.E.; Lee, T.A.; Gibson, T.B.; Marder, W.D.; Weiss, K.B.; Blumenthal, D. Multiple Chronic Conditions: Prevalence, Health Consequences, and Implications for Quality, Care Management, and Costs. J. Gen. Intern. Med. 2007, 22, 391-396. [CrossRef]

11. Nikendei, C.; Terhoeven, V.; Ehrenthal, J.C.; Maatouk, I.; Wild, B.; Herzog, W.; Friederich, H.-C. Depression profile in cancer patients and patients without a chronic somatic disease. Psychooncology 2018, 27, 83-90. [CrossRef] [PubMed]

12. Pan, A.N.; Keum, N.; Okereke, O.I.; Sun, Q.I.; Kivimaki, M.; Rubin, R.R.; Hu, F.B. Bidirectional Association between Depression and Metabolic Syndrome: A systematic review and meta-analysis of epidemiological studies. Diabetes Care 2012, 35, 1171-1180. [CrossRef] [PubMed]

13. Axon, R.N.; Zhao, Y.; Egede, L.E. Association of depressive symptoms with all-cause and ischemic heart disease mortality in adults with self-reported hypertension. Am. J. Hypertens. 2010, 23, 30-37. [CrossRef] [PubMed]

14. Moussavi, S.; Chatterji, S.; Verdes, E.; Tandon, A.; Patel, V.; Ustun, B. Depression, chronic diseases, and decrements in health: Results from the World Health Surveys. Lancet 2007, 370, 851-858. [CrossRef]

15. Montgomery, J.; Lu, J.; Ratliff, S.; Mezuk, B. Food Insecurity and Depression Among Adults With Diabetes: Results From the National Health and Nutrition Examination Survey (NHANES). Diabetes Educ. 2017, 43, 260-271. [CrossRef]

16. Walker, R.J.; Gebregziabher, M.; Martin-Harris, B.; Egede, L.E. Independent effects of socioeconomic and psychological social determinants of health on self-care and outcomes in Type 2 diabetes. Gen. Hosp. Psychiatry 2014, 36, 662-668. [CrossRef]

17. Fraser, S.D.S.; Taal, M.W. Multimorbidity in people with chronic kidney disease. Curr. Opin. Nephrol. Hypertens. 2016, 25, 465-472 [CrossRef]

18. McPhail, S.M. Multimorbidity in chronic disease: Impact on health care resources and costs. Risk Manag. Healthc. Policy 2016, 9 , 143-156. [CrossRef]

19. Fraser, S.D.S.; Roderick, P.J.; May, C.R.; McIntyre, N.; McIntyre, C.; Fluck, R.J.; Shardlow, A.; Taal, M.W. The burden of Comorbidity in people with chronic kidney disease stage 3: A cohort study. BMC Nephrol. 2015, 16, 193. [CrossRef]

20. Nemeroff, C.B.; Goldschmidt-Clermont, P.J. Heartache and heartbreak-the link between depression and cardiovascular disease. Nat. Rev. Cardiol. 2012, 9, 526-539. [CrossRef]

21. Egede, L.E. Major depression in individuals with chronic medical disorders: Prevalence, correlates and association with health resource utilization, lost productivity and functional disability. Gen. Hosp. Psychiatry 2007, 29, 409-416. [CrossRef] [PubMed]

22. Kroenke, K.; Spitzer, R.L. The PHQ-9: A new depression diagnostic and severity measure. Psychiatr. Ann. 2002, 32, 509-515. [CrossRef]

23. Kroenke, K.; Spitzer, R.L.; Williams, J.B.W. The PHQ-9.pdf. J. Gen. Intern. Med. 2001, 16, 606-613. [CrossRef] [PubMed] 
24. NHANES 1999-2000: Food Security Data Documentation, Codebook, and Frequencies. Available online: https://wwwn.cdc. gov/nchs/nhanes/1999-2000/FSQ.html (accessed on 27 April 2021).

25. Defining Adult Overweight \& Obesity / Overweight \& Obesity /CDC. Available online: https://www.cdc.gov/obesity/adult/ defining.html (accessed on 27 April 2021).

26. Piercy, K.L.; Troiano, R.P.; Ballard, R.M.; Carlson, S.A.; Fulton, J.E.; Galuska, D.A.; George, S.M.; Olson, R.D. The Physical Activity Guidelines for Americans. JAMA 2018, 320, 2020-2028. [CrossRef]

27. Katzmarzyk, P.T.; Lee, I.M. Sedentary behaviour and life expectancy in the USA: A cause-deleted life table analysis. BMJ Open 2012, 2, e000828. [CrossRef]

28. Bureau, U.C. Poverty: 2017 and 2018. Available online: https://www.census.gov/library/publications/2019/acs/acsbr18-02 .html (accessed on 27 April 2021).

29. National Center for Health Statistics. NHANES 1999-2000 Addendum to the NHANES III Analytic Guidelines. 1999. Available online: http:/ / www.cdc.gov/nchs/data/nhanes/nhanes3/nh3gui.pdf (accessed on 9 January 2022).

30. National Center for Health Statistics (NCHS)—NCHA. Available online: https://www.ncha.org/glossary/national-centerhealth-statistics-nchs/ (accessed on 27 April 2021).

31. Pryor, L.; Lioret, S.; van der Waerden, J.; Fombonne, É.; Falissard, B.; Melchior, M. Food insecurity and mental health problems among a community sample of young adults. Soc. Psychiatry Psychiatr. Epidemiol. 2016, 51, 1073-1081. [CrossRef]

32. Berkowitz, S.A.; Baggett, T.P.; Wexler, D.J.; Huskey, K.W.; Wee, C.C. Food Insecurity and Metabolic Control among U.S. Adults with Diabetes. Diabetes Care 2013, 36, 3093-3099. [CrossRef]

33. Farr, S.L.; Hayes, D.K.; Bitsko, R.H.; Bansil, P.; Dietz, P.M. Peer Reviewed: Depression, Diabetes, and Chronic Disease Risk Factors among US Women of Reproductive Age. Prev. Chronic Dis. 2011, 8, A119. 